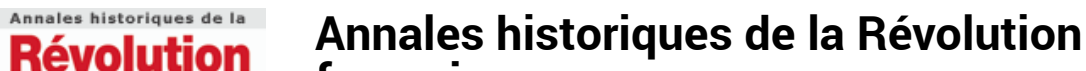

française française

352 | avril-juin 2008

Les temps composés de l'économie

\section{Daniel Rabreau, Le Théâtre de l'Odéon. Du monument de la Nation au théâtre de l'Europe}

\section{Michel Biard}

\section{(2) OpenEdition \\ 1 Journals}

\section{Édition électronique}

URL : https://journals.openedition.org/ahrf/11045

DOI : $10.4000 /$ ahrf. 11045

ISSN : 1952-403X

Éditeur :

Armand Colin, Société des études robespierristes

\section{Édition imprimée}

Date de publication : 1 juin 2008

Pagination : 300-301

ISBN : 978-2200-92514-7

ISSN : 0003-4436

\section{Référence électronique}

Michel Biard, «Daniel Rabreau, Le Théâtre de l'Odéon. Du monument de la Nation au théâtre de l'Europe ». Annales historiques de la Révolution française [En ligne], 352 | avril-juin 2008, mis en ligne le 18

décembre 2009, consulté le 23 avril 2022. URL : http://journals.openedition.org/ahrf/11045; DOI : https://doi.org/10.4000/ahrf.11045

Ce document a été généré automatiquement le 23 avril 2022.

Tous droits réservés 


\title{
Daniel Rabreau, Le Théâtre de l'Odéon. Du monument de la Nation au théâtre de l'Europe
}

\author{
Michel Biard
}

\section{RÉFÉRENCE}

Daniel Rabreau, Le Théâtre de l'Odéon. Du monument de la Nation au théâtre de l'Europe,

Paris, Belin, 2007, 190 p., ISBN 978-2-7011-3304-1, $23 €$

1 Professeur d'histoire de l'art moderne à l'Université Paris I, Daniel Rabreau est l'auteur de plusieurs ouvrages de qualité consacrés à la Saline Royale d'Arc-et-Senans et à l'architecte Claude-Nicolas Ledoux. Il retrace ici l'histoire du Théâtre de l'Odéon, en suivant notamment les projets de deux architectes majeurs du XVIII ${ }^{e}$ siècle, qualifiés par lui d'«avant-gardistes», Marie-Joseph Peyre (1730-1785) et Charles de Wailly (1730-1798). Le dernier est sans doute plus connu de ceux qui étudient la Révolution française, en raison de ses engagements politiques et des diverses charges qu'il a accepté (entre autres, une mission en Belgique et Hollande pour l'inventaire des objets d'art et de sciences, notamment étudiée il y a quelques années par Christophe Loir dans un livre consacré à $L a$ sécularisation des œuvres d'art dans le Brabant [...], dont il a été rendu compte dans les AHRF, nº 3-1999).

2 Le premier projet lancé en vue de l'édification d'un théâtre destiné à remplacer la vieille salle de la Comédie-Française, construite en 1689, date des années 1760, et Soufflot est alors l'architecte pressenti. Mais, en 1767, Marigny, Directeur des Bâtiments du Roi, charge du projet deux autres architectes, Peyre et de Wailly. S'ensuivent alors dans les années 1770 diverses tergiversations et intrigues, avec des projets concurrents (Liégeon, puis Moreau), avant que les travaux commencent en 1779, avec un autre roi et un autre Directeur des Bâtiments (d'Angiviller). L'inauguration a finalement lieu le 9 avril 1782, en présence de Marie-Antoinette, après 
qu'un arrêt du Conseil du roi eut ordonné, en février, l'installation des ComédiensFrançais dans le nouveau théâtre. Daniel Rabreau analyse de façon très détaillée l'évolution des projets de Peyre et de Wailly. En 1767-1769, ils ont d'abord pensé à un théâtre en demi-rotonde, situé au bout d'une longue avenue plantée. Le second projet, en 1770-1774, opte pour un " théâtre-bloc » rectangulaire, avant qu'un troisième projet modifie encore celui-ci en 1776-1780. Au final, le théâtre, de plan rectangulaire, est entouré d'arcades libres d'accès et s'inspire des édifices sacrés grecs, " théâtre-temple » à l'antique au cœur d'un quartier lui formant une sorte d'écrin. Le théâtre s'élève en effet sur une place en hémicycle qui, par sa forme, annonce le spectacle dans l'espace urbain; cinq rues rayonnantes mènent vers sa façade ornée d'un portique à colonnades, trois autres l'isolent sur ses côtés et son arrière pourvus d'arcades. Le « chef-d'œuvre » de Peyre et de Wailly contient 1900 places, avec un parterre assis. De nombreuses reproductions de dessins et gravures, de plans, ainsi que des photos (tant anciennes que récentes) accompagnent le livre de Daniel Rabreau et permettent d'avoir une idée précise du tout. Tout au plus, peut-on regretter l'absence d'un plan de Paris permettant de situer l'ensemble des salles de spectacle, là où les plans fournis ne donnent que la situation du Théâtre de l'Odéon, entre le Luxembourg, l'église des Cordeliers et la foire Saint-Germain.

3 C'est dans ce théâtre qu'est donné en avril 1784 Le Mariage de Figaro, et c'est encore dans cette salle que les Comédiens représentent le Charles IX de Chénier en novembre 1789, le Théâtre-Français étant alors devenu Théâtre de la Nation. L'auteur suit alors la vie de cette salle, qui ferme ses portes en 1793 lorsque les Comédiens sont arrêtés après la représentation de Paméla. Elle rouvre ses portes en juin 1794 sous le nom de Théâtre de l'Égalité, après que pendant plusieurs mois eut été discuté un projet d'y installer un opéra, notamment sur la suggestion de Wailly. La nouvelle salle est mise au goût du jour, avec peinture tricolore et surtout une structure de "gradins égalitaires à la grecque ». Le théâtre ferme à nouveau en 1795, rouvre en 1797 pour la première fois sous le nom de Théâtre de l'Odéon et avec des loges rétablies. Reprise éphémère, puisqu'il doit fermer au bout d'un mois ! Oserais-je écrire qu'il renaît une fois de plus de ses cendres en 1798 ? «Le 19 février 1799 [le directeur] Sageret démissionne tandis que la troupe, formée en société provisoire, poursuit les spectacles. Le 15 mars, un procèsverbal constate un déficit de 150000 francs; un des anciens associés, Le Page, refuse de le signer, affirmant qu'il "mettrait plutôt le feu à la salle que de signer sa condamnation". Trois jours plus tard, le théâtre était la proie des flammes!» Parmi les volontaires qui luttent contre les flammes, le propre fils de Peyre... Cette fois, le théâtre n'allait rouvrir qu'en 1808, sous le nom de Théâtre de Sa Majesté l'Impératrice et Reine, avant que la Restauration lui redonne le nom de Théâtre de l'Odéon, puis qu'un nouvel incendie le ravage en 1818. La renaissance fut rapide, puisqu'il rouvrit dès 1819, avant de connaître toute une nouvelle vie, des avatars successifs et d'autres restaurations, dont la plus récente date de 2006.

4 L'ouvrage de Daniel Rabreau est important aussi bien pour ceux qui s'intéressent à l'architecture du siècle des Lumières que pour ceux qui se passionnent pour l'histoire du théâtre. Sans doute rencontrera-t-il son public, en tout cas nous ne pouvons que le souhaiter. 